\title{
Urban landscape assessment
}

\author{
Vicente Collado Capilla ${ }^{1}$, Sonia Gómez-Pardo Gabaldón² \\ ${ }^{1}$ Green Infrastructure and Landscape Service. Valencia Region. Spain \\ ${ }^{2}$ Territorial Planning of Valencia Service. Valencia Region. Spain \\ E-mail: vcc.arq@gmail.com sgpg.sgpg@gmail.com
}

\begin{abstract}
The valuation of the urban landscape as an important element in the quality of life and the sustainable development of the city constitute an incipient field of investigation from a new perspective that adds meanings and values. It starts from the concept of valuation as a system where the tangible and intangible values that the population and the experts assign to it are considered. These include formal, economic, environmental, social, cultural... issues and the relationships among them. The consideration of the opinions of experts from different disciplines, together with the preferences expressed by the population regarding the spaces they inhabit on a daily basis and their aspirations, strengthen the sense of belonging and the identity of the place as key elements in the perception of landscapes Urban that allows to contribute new qualities, criteria of integration and contemporary values to any type of intervention. These strategies and intervention procedures start from the complexity of the city as a system and incorporate the perception that citizens have or will have of their immediate environment. An analytical-qualitative methodology is proposed for the appraisal of the urban landscape assessment by the experts based on the systemic and perceptive factors that characterize the landscape. Its practical application to the Campanar area in Valencia has allowed us to validate it as a process that leads to the identification of values, pressures and driving forces; the evaluations are carried out in terms of quality objectives and actions to improve the quality of the urban environment.
\end{abstract}

Keywords: urban landscape, streetscape, landscape value, landscape assessment, landscape preferences.

\section{Urban form and landscape}

From the European Landscape Convention (ELC, 2000) we mean by landscape any part of the territory, in our case the city, as it is perceived by the citizens. The character, the structure that gives it identity, is determined by certain natural and / or human factors and their relationships, it is an open system, in terms of systems theory, or an ecosystem, while relations are given among them and their environment.

The urban form and the physiography of the environment are the structuring factors of the urban landscape. Public space and edification (architecture) that give corporeity to the urban scene, are the fixed elements, the scenic background. On them are articulated others of variable character such as gardening, urban furniture or those linked to human activities; and moving elements such as vehicles, animals and people, elements of the landscape and recipients of it.

We can talk about landscape because all these elements are perceived (Goldstein, 2011). The city, understood as a system, is the object and the landscape, its perception by the population. The factors that characterize an urban landscape may belong to the system (systemic) or to its perception (perceptive). 


\begin{tabular}{|l|l|l|l|l|}
\hline TYPE / SCALE & GLOBAL LANDSCAPE & $\begin{array}{l}\text { SETTLEMENT } \\
\text { LANDSCAPE }\end{array}$ & $\begin{array}{l}\text { INTRAURBAN } \\
\text { LANDSCAPE }\end{array}$ & URBAN SCENE \\
\hline AMBIT & City or metropolitan area & Urban edge & $\begin{array}{l}\text { Neighborhood, Landscape } \\
\text { area }\end{array}$ & $\begin{array}{l}\text { Street, square, } \\
\text { crossing }\end{array}$ \\
\hline $\begin{array}{l}\text { PERCEPTION } \\
\text { POINT }\end{array}$ & External / internal & External & Internal & Public space \\
\hline PLANNING & $\begin{array}{l}\text { Master Plan } \\
\text { Regional Plan }\end{array}$ & $\begin{array}{l}\text { Master Plan } \\
\text { Development plan }\end{array}$ & $\begin{array}{l}\text { Development plan } \\
\text { Urban Project }\end{array}$ & $\begin{array}{l}\text { Development plan } \\
\text { Urban Project } \\
\text { Urbanization project }\end{array}$ \\
\hline
\end{tabular}

Figure 1. Scales of urban landscapes

Among the perceptive population, we can distinguish two types: the experts, who require justification of scientific or technical basis of their branch of knowledge in their judgments and non-specialists, who establish them from the experiences lived there depending on your feelings, emotions and intentions; a statistically representative number of them can be considered an opinion of the population.

The perception of the city and its forms varies according to the scale and points of perception linked (Image 1). The global urban landscape is what gives us the bird's eye view and covers the entire city or metropolitan area and its surroundings; in the extra-urban or settlement landscape, perception is formed from its edges and accesses and in the intraurban landscape, the city is perceived from within, strongly linked to the urban form, its architecture, its public space and the relations between both. Linked to this we find the urban scene or limited public space with which the perceiver is placed in sensory relation and establishes long bonds in the form of emotions and feelings (Lynch, 1960).

\section{The process of attaching value}

The urban landscape assessment is the process of issuing judgments linked to the perception of the city. These judgments can vary depending on the purpose or interest, times, social groups, knowledge of the place, etc. The Council of Europe (2013) considers that the landscape bears within it value systems that integrate social values, heritage values -both natural and cultural- and economic value. Punter (1982) comes to consider that valuation is a phase of perception. For Aguiló et al. (1998) the value that is assigned to a landscape has interdependent components that are knowledge, feeling and emotions that form an interrelated complex value system.

We understand by quality the judgments emitted only by experts. Quality is an incomplete value. The assessment of a landscape requires knowing the quality set by experts, and the judgments and aspirations of the rest of the population (resident and transient) (Collado and Gómez-Pardo 2007).

It can be expressed in a qualitative way whose communication capacity has no limits or quantitative used by the objective aspect that the mathematical figures transmit although they continue transmitting subjective judgments.

The methods according to the criteria used may be synthetic, analytical and mixed (Aguiló et al., 1998; Hallet, 1996). Synthetic methods (also called global or direct) understand perception as a holistic process, which proposes that what we experience is more than the sum of its parts. The valuation, of subjective character, is made from the consideration of the landscape as a whole. Analytical or indirect methods perform the assessment based on the analysis and description of landscape components, usually weighted with categories and statistical methods of classification. These methods tend to be longer and more costly. At present many of the methods combine the two approaches, synthetic and analytical, in order to accumulate the advantages of both.

Of the most relevant international experiences, we highlight the American methods of assessing the visual and sound landscape (Smardom et al., 1986; Shaffer 1977) against the English methods of assessing the landscape character with its Landscape Character Assessment, and its two phases: characterization and the issuance of judgments or opinions (Swanwick, 2002). 
Methodological proposal for the urban landscapes assessement by experts

Based on the postulates of Landscape Character Assessment and ELC (2000), integrated in the Valencian landscape legislation, we propose a mixed, analytical-qualitative method for the technical evaluation phase, or quality, of urban landscapes to from the defining factors of their character. This does not affect to the valuation by the population.

The issuance of a judgment by an expert seems to be linked to the analysis. We could say that there is no pure global value of an expert regarding issues that are the subject of his study or work. It is very convenient that it be so because, although the judgment is subjective, it must be reasoned and respond to an absolutely rigorous and grounded analysis. Objectivity in absolute terms does not exist, but the tendency resulting from the judgment of a panel of experts and the preferences expressed by the population can be somewhat similar.

Analytical methods have usually been linked to forms of quantitative expression, which in our view, distract from the value of their purpose. Valuation concerns the whole process, which allows us to identify its state (deficiencies, satisfactions, potentialities, trends, dynamics, objectives, etc.) and propose the measures and actions necessary to reach the quality parameters desired by the People who inhabit or transit. Landscape intervention requires the phases of identification, characterization, assessment, proposal of quality objectives and actions (Council of Europe, 2000). Valuation is not an end in itself but an instrumental phase of the process.

We conclude by talking about perception in the differentiation between systemic factors -linked to the city understood as an open systemand perceptual factors -all of which make us perceive it in a certain way-. From the own investigations developed since 2007 as well as from AGUILÓ et alt. (1986), ESTEBAN Y NOGUERA (1981), HALLET (1996), LYNCH (1960), MATA (2003), PANERAI (1986), RUEDA (2012), SMARDON (1986), SOLÀ MORALES (1997), SWANWICK (2002) and
ZOIDO (2010), we propose Images 2 and 3 in which some of the main factors of the character of urban landscapes and their perception are structured.

From a complete prior characterization of the landscape, a complex and global structured assessment could be undertaken in a manner similar to that characterization factors that have been organized. For a more clear exposition of the analytical-qualitative method that is defended, an example of an evaluation of the character of the urban landscape for Campanar area in Valencia is shown below. (Image 4).

It is necessary to identify certain limitations of this proposal because evident limitations of space and frame (urban morphology). First, the assessment is made by the authors and not by a panel; this lack of space and frame has been addressed using suitable bibliographical sources. We do not collect the previous characterization, but the tables that we propose for its elaboration. We trust that the references in the text will bring the reader to the elements being evaluated. The necessary perception studies and their corresponding maps are not incorporated. Neither have the preferences of the population, derived from participatory processes, which must be taken into account and limited to technical evaluation or quality, have been collected.

\section{Example of technical evaluation from the character of an urban landscape: Campanar area in Valencia.}

\section{Territorial integration}

The plain, water and climate are the physiographic base of the territory on which the city of Valencia is based and allow for the development of the Huerta, a space with a geographical structure and singular landscape with a spatial pattern and cultural elements and peri-urban agriculture of high international value. Urban growth often leads to irremediable loss of soil with a great agricultural wealth and the loss of population and the millenary culture linked to it, having been and being the main territorial tension that causes a significant loss of values of the old rural landscape of the Huerta. 


\section{SYSTEMIC FACTORS}

TERRITORIAL INTEGRATION FACTORS

Physical environment

Climate, geomorphology, soil, water, vegetation cover and fauna. Territorial structure and processes of occupation of soils. Landscape areas

Green Infrastructure

Basic territorial system composed of the areas of most relevant environmental, cultural, agricultural and landscape value; the critical areas of the territory whose transformation involves risks or environmental costs for the community; and the territorial framework of ecological corridors and functional connections that relate all the above elements.

Settlement Landscape

Skyline of the settlement; Facade or edge conditions; Composition of volumes. Relationship with their environment from the main points of perception, especially access to the settlement.

Skyline of the settlement; Facade or edge conditions; Composition of volumes. Relationship with their environment from the
Color and texture. Unique elements: milestones and impacts. Landscape fragility. Acoustic, olfactory and tactile sensations.

Urban Integration

Relations with the existing urban and metropolitan structure; connection to adjacent tissues and potential connectivity on foot, in non-motorized vehicles and public transport network; effects on the parcel structure and the pattern of settlement of the buildings.

Urban Metabolism

Consumption and availability of metabolic resources (water, energy, building materials, food production) and the capacity of solid waste recycling and effluent treatment. Emission of

Consumption and availability of metabolic resources (water, energy, building materials, food production) and the capacity of solid waste recycling and effluent treatment. Emissi
pollutants in relation to the capacity of the atmosphere to disperse them. Acoustic, luminous and electromagnetic conditions; population exposed to levels not allowed by law.

Climate change

Mitigation of its effects and resilience or adaptability to new scena rios (floods, water resources decrease, te mperature increase, forest fires).

SOCIO-CULTURAL FACTORS

Population

Composition of the population according to profiles of age and sex, maternity/paternity; level of occupation by sectors and average income; life habits; consuming patterns.

Social inclusion

Level of social inclusion regarding age, sex, ethnic origin, disability, etc .; access to housing and equipment. Vulnerable urban spaces.

Culture

Historical; cultural activities; symbolic; cultural patterns of the population; associationism.

DRIVING FORCES

Politics

Policies that can produce, directly or indirectly, significant changes in the patterns of landscapes or their perception, or promote the achievement of the objectives of landscape quality.

Economy

Economic value of the landscape and its weight in the productive sectors. Profile of the companies, annual volume of work differentiating by uses and types, urbanized area, etc. Patterns of preference (which is and how the product is accessed, which landscape factors a re willing to pay, fashions, referrals), production (self-promotion, small promotion, promotion linked to soll preference (which is and how the product is accessed, which landscape factors are willing to pay, fashions, re
operation) and marketing (direct, local operators, promotion at the regional, national or international level).

Legislation

Legislation on environmental issues, land use planning, town planning, housing, property rights, landscape and those related to the management and governance of the territory and urban areas. Plans, programs and projects

Public opinion

Media and other opinion and fashion generators that influence the preferences of the population with respect to their environment

URBAN MODEL FACTORS

Materiality

Density and soil occupation; buildability; internal structure of the neighborhood or functional unit: location of facil ities and public spaces, layout of the road network. Centralities. Network of spaces for dailv life.

Functionality

Mobility by private vehicles, public and non-motorized transport. Complexity in urban uses; ident fication of mono-functional nuclei with exclusive patterns.

FACTORS OF THE URBAN FORM

Urban Fabrics and Systems

Urban fabrics: Historic center, Ensanche, Compact, Open-plan construction, Single-family dwelling, Polygons, Suburban, Marginal, Tertiary, Industrial. Systems: road, transport, equipment, infrastructure. etc.

Public space

Types, plant, trace, section, perimeter materialization, mate rials, topography. Habitability of the public space, vegetation. Structure of the collective image of the city (Lynch): itinera ries,

landmarks, nodes and borders. Landscape fragility

Building Types

Use, type, use of ground floor, plot, location in building plot, volume or number of floors. Covers

Forms of buildings grouping on the block or urban unit

Architecture

Style, school, age, author, patterns. Ground floor and plant type, section, facades: color texture of the enclos ing materials, rhythm (facade width), composition, grain (of bodies flown), decorative elements.

\section{OTHER ELEMENTS OF THE URBAN SCENE}

\section{Variable elements}

Gardening: Morphology, species, size /age, color, annual cycle

Ground-floor: Use dominant advertising, relation with the public space (occupation with ta bles exhibitors, awnings, etc).

Use of public space: Private motorized traffic, private non-motorized traffic, pedestrian circulation, parking, terraces, games, sports, tents, fairs, parties, relaxation, communication, demonstrations. Ephemeral Art

Urban furniture : Type of pavement: material, color and texture; type of Lighting: design, color of light, level of Brightness $y$; type and elements of furniture: design, materials. Type and Urban furniture : Type or

Mobile Elements

People: Volume, exclusive use of public or shared space, activities. Residents, tourists. Ethnicities

Vehicles: Type (motorized, non-motorized), volume of traffic, speed and noise, surface parking, he avy traffic. Shared or exclusive use of space with non-motorized vehicles and pedestria ns.

Public transoort.

Animals: urbanized wildlife (rodents, insects, birds, etc.) pets

Immaterial elements

Climate: sun exposure, color of the sky, quality of the air.

Time: Evolution of the scenes perceived throughout the daily and annual cycle

Safety: Lighting, traffic of people and vehicles, use of low floors, length of routes without escape or help.

Cleaning: waste in the streets and public spaces, waste containers, remains of recreational and festive activities, lack of maintenance of facades and urban furniture.

Figure 2. Factors of characterization of the urban landscapes. Systemic factors 


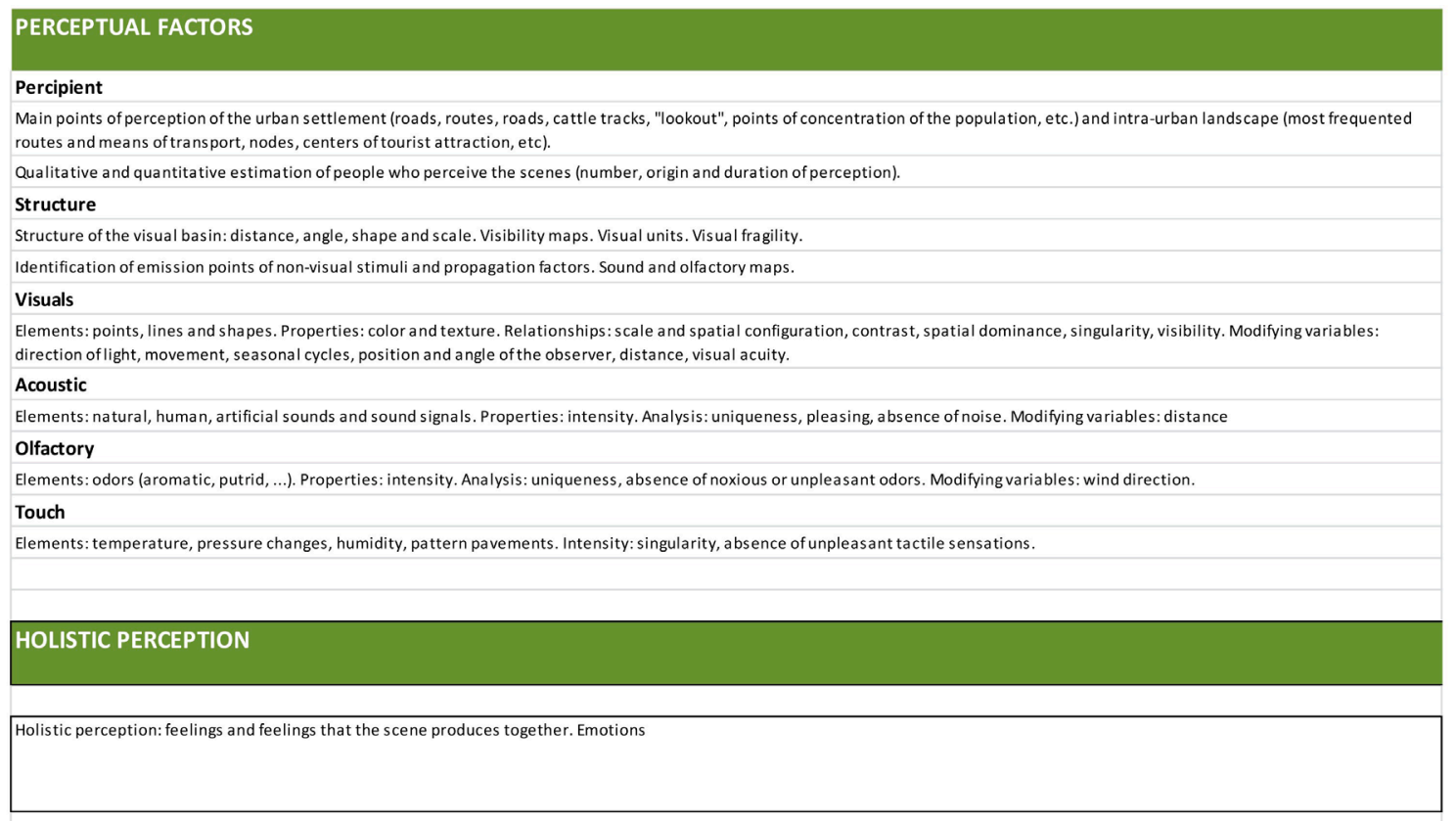

Figure 3. Factors of characterization of the urban landscapes. Perceptual factors

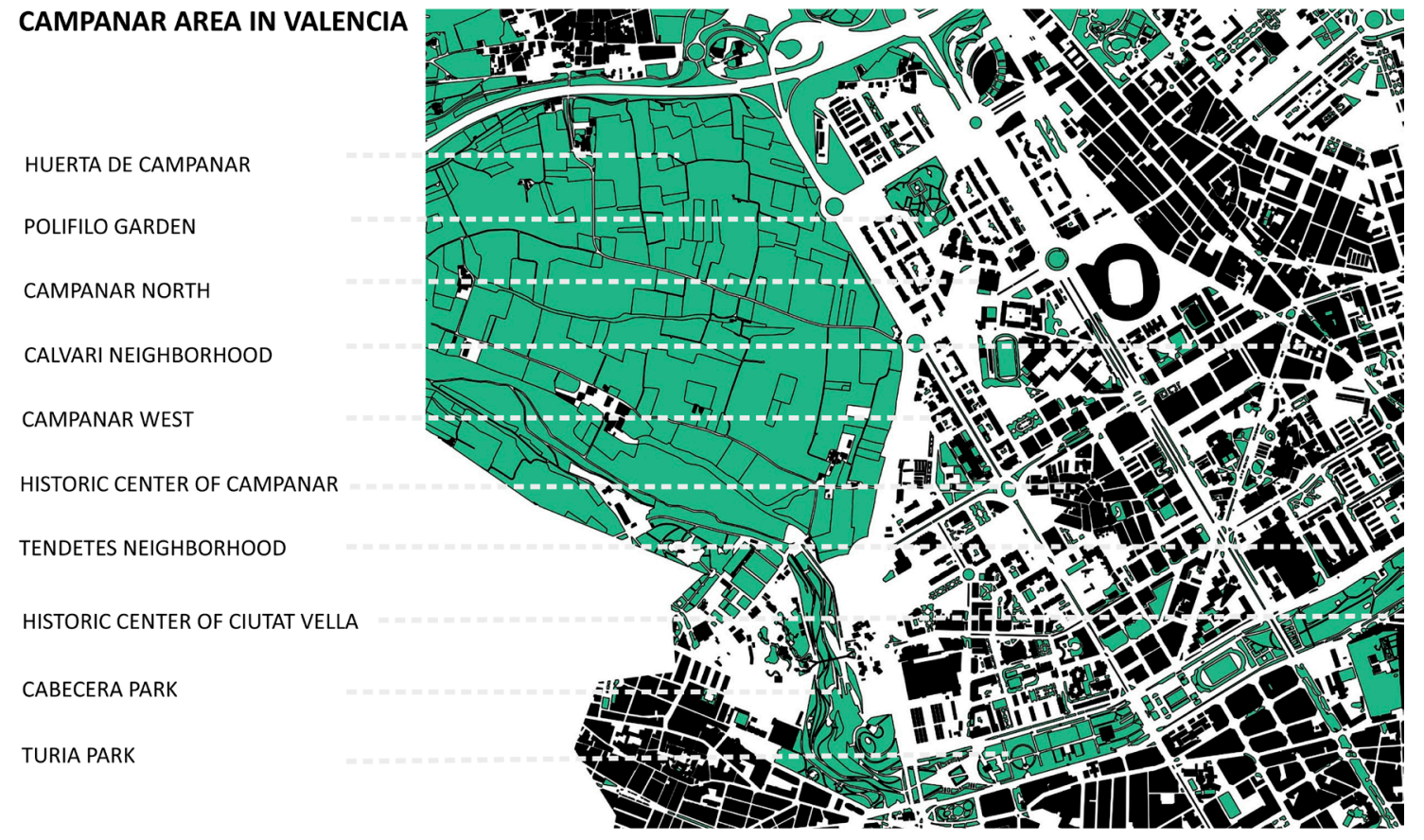

Figure 4. Map of the area of Campanar 
Campanar is functionally integrated by means of powerful roads, which offer certain advantages, but with a negative balance: they break the continuity of the roads that cross it (Campanar and Paterna roads), they cause excessive distances between crossings for pedestrians, turning onto an inaccessible barrier; the intense traffic is a focus of atmospheric, acoustic and visual pollution and in its metropolitan section (CV-30) they break the continuity of the Huerta de Campanar with the one of Paterna being confined; it isolates important elements of the Urban Green Infrastructure (River, Turia park, Cabecera park, garden of Polifilo, and rest of the Huerta de Campanar) that could bring greater landscape, environmental and cultural value, in addition to an incipient tourist attraction.

It was a municipality located to the north of the river Turia with its small rural nucleus and its huerta crossed by roads, ravines and ditches until its annexation with Valencia. The few remaining historical remains have an interesting environmental, social, patrimonial and cultural value at a local level. The ancient nucleus that is the best-preserved part, with the church and its powerful bell-tower, is only rarely visible from the neighborhood, but preserves the rural character of the settlement of high identity value.

Its edges, seen from the Turia Park, the viewpoint of the Cabecera Park, the Huerta de Campanar and the access from the Ademuz motorway, form emphatic volumes, crowded, without rhythm or clear criteria of composition. The south front, which flows to the Turia Park, has a high-block treatment, creating a screen, interrupted by three large containers (two shopping centers and the bus station). It is worth noting the modern movement town planning scene that is observed from el Puente de les Arts with three serial front screens, the same treatment of neutral facade and an encounter with street level articulated by by a green area that minimizes its height. In the extreme west, the execution fails to meet the initial proposal. From the facade recessed to the Huerta it is worth noting the excessive height and the interruption on the agricultural mesh and the pattern of this periurban agrarian landscape so flat and open with a high value. From the CV-35 there is a structured scene and with modern neutral architecture from Hall of Congress by Foster, but of an excessive scale for its territorial integration (Image 5).
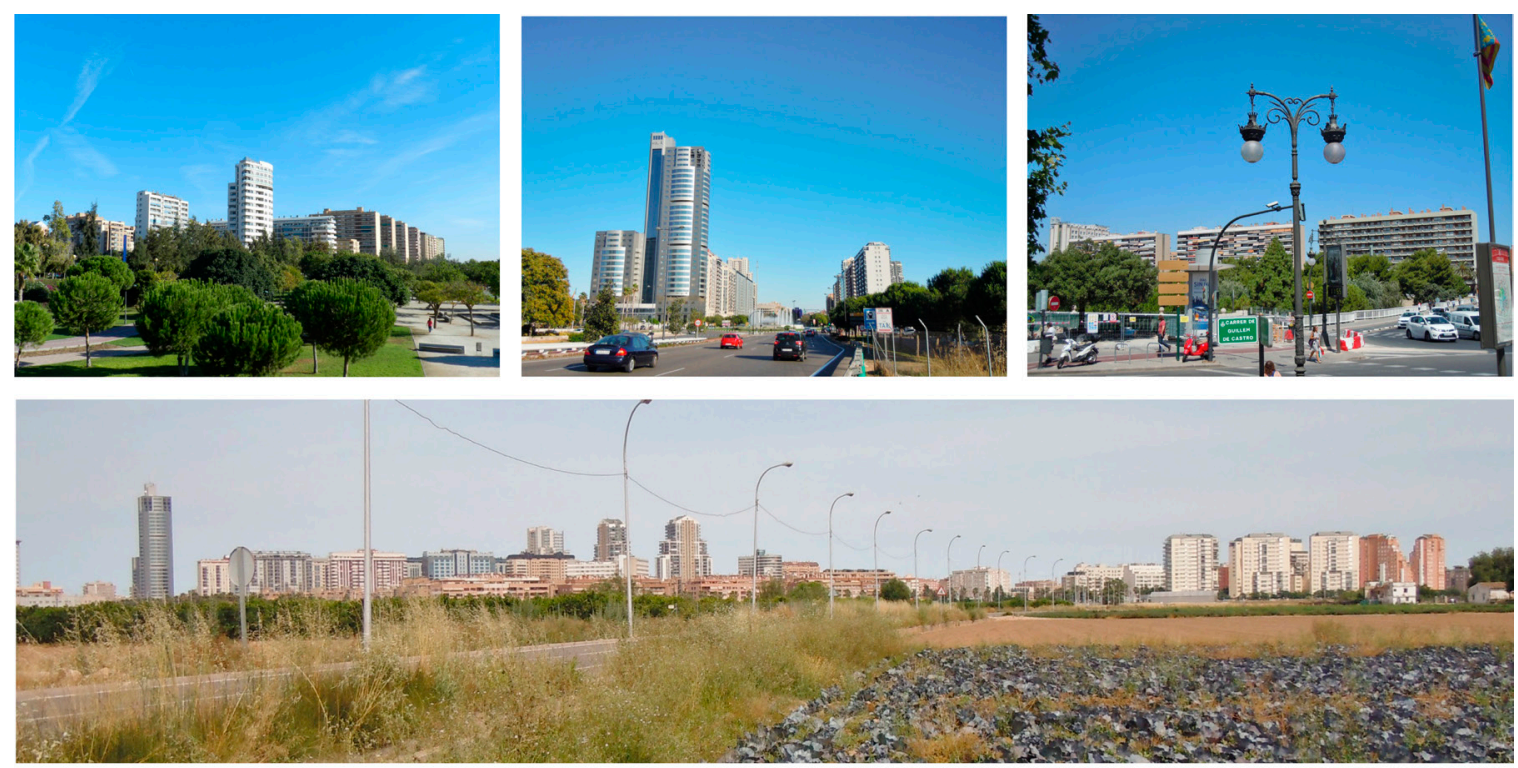

Image 5. Settlement Scenes

A) Facade of the Turia Park. B) Ademuz motorway facade. C) Facade of the Turia Park. C) Facade Huerta de Campanar 


\section{Socio-cultural factors}

With 37.084 inhabitants, the area has $10.6 \%$ of its population at risk of urban vulnerability based on municipal demographic and socioeconomic data (2016), concentrating on the Calvari neighborhood.

The population is based on socio-economic profiles, with some symptoms of exclusivity. The population of the central third, which embraces the old Campanar, responds to middle classes seated on an ordinary landscape. The latest developments in the west and north (Sant $\mathrm{Pau}$ ) offer settlement models that respond to the type of residential area closed with common services (swimming pool and play areas) with a social exclusivity that generates a landscape very much appreciated by a population of high socio-economic level.

The population lives without conflicts. According to the municipal survey of 2017, it appreciates the values of security, tranquility and neighborhood coexistence. Also the proximity to the center of the city and the offer of services throughout the neighborhood and rejects the dirt it presents. There are various cultural and social associations and various citizen platforms.

\section{Driving forces}

The planning of this zone begins with the Valencia Metropolitan Plan (1946) and the Law of Limited Rental Housing (1954). It coincides with the stage of greater demographic and urban expansion of Valencia in the 60's, when the creation of the metropolitan area was formed. Master Plan of 1966 will originate development plans in the area. Finally, with the Master Plan of 1988 and the new Valencian Urbanism Law (LRAU 1994), the area that remains to be developed in Campanar becomes a test bed for the new urban planning instruments. In terms of power, the urban form went from being in the hands of public power, which must offer integrated and long-term quality growth for its citizens (1946-1994), to being in a strong economic sector that competes to offer the market attractive products and maximum profitability (developer).

The revision of Master Plan (paralyzed in 2011), provided for the reclassification of Huerta land in the new sector (R-6) and the union project of the V-30 with Master Rodrigo avenue (round of Mislata). The Territorial Action Plan of the Huerta de Valencia (Generalitat Valenciana, 2016) and the Natural Resources Management Plan of the River Turia, could return the value to the Huerta de Campanar once again. The Urban Land and Rehabilitation Law (2015) and Planning and Landscape Use Law of the Valencian Region (2014) can be the engine for new values for urban regeneration.

\section{Factors of the Urban Model}

The studied area does not respond to a single plan but to three partial plans, from different times developed with tensions and modifications (Pérez Igualada, 2005), accompanied by a progressive loss of urban quality. We will differentiate between Center Campanar (PP8) delimited by the current Burjasot avenue, General Avilés street, Maestro Rodrigo avenue and Turia Park; the West Campanar (PP8-B) adjacent to the former and delimited by these three axes and by Pío Baroja avenue; and North Campanar (PP24-A) developed to the north of General Avilés street and around Valencian Cortes avenue.

It dominates the construction of isolated blocks in height and large pieces destined to commercial centers, hospitals, educational, sports, administrative and service centers that break the projected form and add elements of urban and metropolitan centrality. Based on data from the municipal census (2016), the total density is 74 housing per hectare and 150 habitant per hectare with a compactness, in terms of gross residential building index (RBI) of $1.26 \mathrm{~m} 2 \mathrm{tr} / \mathrm{m} 2 \mathrm{~s}$, aceptable values from the point of view of sustainable urbanism, slightly below those proposed by Rueda (2012) (100160 housing per hectare and 200-400 habitant per hectare).

It is structured by large routes, arranged in mesh allowing for a super-block with sides of 500 to 600 meters. The intensity of road traffic and average speed is very high, degrading the quality of the public space and being a focus of environmental, noise and visual pollution. The traffic on the interior roads is medium level and 
the parking pressure causes a degrading effect of the public space. The building is surrounded by an important network of free spaces, with enough vegetation. In general, they are of average quality, although appreciated by the resident population and of low legibility, the zones of Tendetes and surroundings of Valencian Cortes avenue should be excluded.

The district presents a mixture of uses and segments of population that enrich the urban scene by the flows that it generates. The ground floors are generally reserved for tertiary uses (shops and varied services). This general rule separates the northern zone with buildings of exclusive and selective residential use. The pedestrian mobility, both internal and of passage is abundant and the public transport service balanced with the average of the city. Its compactness makes its maximum dimensions $(2 \mathrm{~km}$ north-south and 1.75 eastwest) and its distance to the center of Valencia ( $3 \mathrm{~km}$ maximum and $1.75 \mathrm{~km}$ average) provide perfect conditions for pedestrian movement and by bicycle, increased by the flat profile and mild climate.

\section{Factors of the Urban Form}

To the East, of Tendetes neighborhood, the blocks of five floors constructed by cooperatives, with housing on ground level; are articulated in serial form flanked by buildings of greater height and commercial use on the ground floor in the North and South fronts; to the East the first closed blocks built according to the Master Plan of 1946 are maintained. The trace of the inner road is arborescent with pressure by the parking lot. On the facade, only bodies are seen flying in the form of open terraces. It provides a scene of a certain quality from the urbanistic point of view.

In the center, around the old town of Campanar, the blocks are privately already built in accordance with the Development Plan of 1961 and of mixed use with commercial business on the ground floor that serves as a union by pairs of blocks of two space from $\mathrm{V}$ to VIII floors, forming small blocks that are perceived at street level as if it were a closed building in compact block. These units are articulated by seriation perpendicular to the main communication routes, being representative the series of Vall de la Ballestera. Altogether it is an ordinary landscape of average quality. Campanar historic center maintains its fabric of historical center with typology of cases de poble (country houses) and semi-detached and a public space of domestic scale that provide scenes of interest. All this isolated from the outside by the blocks that surround it. (Image 6)

To the West, an urban transformation developed from a business initiative (PAI PPR-11 and
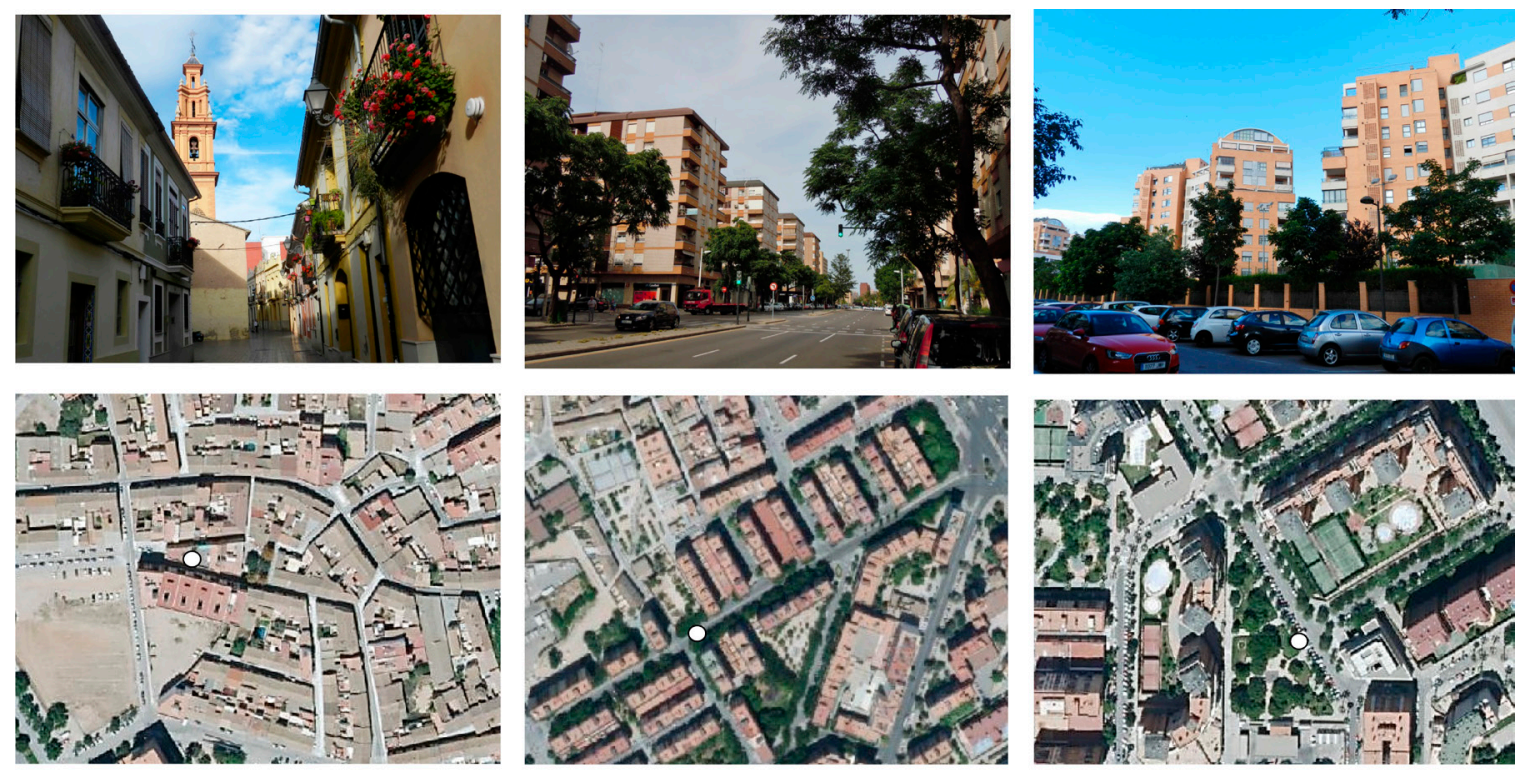

Image 6. Urban scenes and forms

A) Historic Center of Campanar b) Modern City XX century c) New developments XXI century 
PPR-12) with open construction and private equipment in a closed plot. It maintains the tracing of the great routes of rapid circulation with the resulting super-block in whose interior, independent form promotions of high blocks are developed without common structure. In the ground floors, commercial use alternates with the fenced plot that separates public space from private community equipment with exclusion profiles. Urban form generated by the demand that generates a varied but disordered landscape and of dubious urban quality.

To the north of General Avilés, there is a first crown developed based on the old PP-24A of 1975 , which is the most structured, with low open construction. The second, PPR-1 of 1991, absorbed the complex of the Professional Schools of San José, on a large plot of the rustic layout, superimposing a reticular arrangement with super-block outside the territorial structure on which it was based. Around the powerful axis of Valencian Cortes avenue (section greater than 100 meters), linear blocks of XV plants of neutral architecture, interrupted in the crossings by singular buildings of questionable quality. The set defines a singular power scale. Commercial activity in ground floor is maintained. A second line is materialized by units constituted by isolated blocks of alignment forming semi-enclosed blocks with internal community equipment. The low floors are destined to houses that are separated from the exterior public space by enclosed terraces of opaque vegetable fence. This generates a scenic background with acceptable architecture but static and empty in daily life.

\section{Other elements of the urban scene}

In the background constituted by the urban form the variable, moving and intangible elements present in the city play a very important role in the configuration of the landscape and the urban scene.

The surface of public space occupied by cars, in circulation or parked, is excessive, this being the reason why its habitability is low around the roads as well as in the most isolated ones. The number of vehicles also generate acoustic, visual and atmospheric pollution that is the direct cause of a very high value decrease in all the studied areas.
The use linked to commercial exploitation of public space (especially pub terraces, restaurants and coffee shops) is worrying in some areas of greater of pedestrian traffic, although there have been no cases of expulsion of pedestrian activities and nocturnal rest. Medium-sized commercial spaces with their own image dominate the neighborhood. The presence of banal elements is scarce and linked especially to shopping centers.

The vegetation and water always add a lot of value to the urban landscapes. The second one is present in the Cabecera Park, garden of Polifilo, irrigation channels and fountains. The public space is well endowed with gardening, although a more careful selection of species that provide shade and reduce the sensation of heat in the environment is lacking. Porous pavements are remarkably scarce. Of the hard pavements it is lacking the uniform treatment of the same and of the urban furniture that, in general, do not add value.

\section{Perceptual factors}

For the evaluation of the exterior landscape or landscape of the settlement, we have chosen as points of perception the urban edges of the Sant Jose Bridge, the Campanar bridge and the Turia Park; Observatory of Cabecera park, Huerta de Campanar and access by Ademuz motorway. For the interior landscape, the main articulating routes and the internal routes of the assessed area were routed a different times.

From the visual factor, we must refer to color and texture. The area does not have a definite color, its use is random and its range unlimited, from the browns in all its variants to pure and metallic colors. The perception of urban green is acceptable but can be improved. The same occurs with texture, but with mastery of the brick that coexists with the polished surfaces.

The acoustic factor of background noise is present continuously in all areas, being more pronounced in the fast and intense circulation routes, descending in the internal zones and disappearing in the center of the old Campanar with an atmosphere of calm where the square recovers the sound of the children's games and the bells.

With regards to the sense of smell, air pollution prevents any smell, except in open 
spaces such as the Turia Park or the Huerta de Campanar, and there are no unpleasant odors. From the tactile point of view, the texture of hard artificial pavement is almost continuous, with few spaces with natural porous pavements. There are few textures in the building, the street furniture or the green areas that invite to be touched. There are no noticeable differences in temperature and humidity sensations compared to the rest of Valencia, except in the Huerta and river area.

\section{Overall rating}

The Campanar is an ordinary landscape with the character of the modern movement in the south part and of expression of economic power and market urbanism to the north. The scene dominates the disorderly episodes, with low readability, with strong pressure of motorized traffic and parked vehicles, low habitability of the public space and areas of social exclusion. Nevertheless it has an acceptable presence of green and with large areas of complexity in uses and people and with a remarkable identity in the past (the old Campanar and its Huerta) despite the loss of physical references. The imperceptible elements of light, climate and character of the population and the proximity to important elements of the Urban Green Infrastructure make that the residents positively value their belonging to the neighborhood by the feelings of tranquility, security and coexistence.

\section{References}

Aguiló Alonso M. et al. (1998) Guía para la elaboración de estudios del medio físico, pp481-546 (Ministerio de Medio Ambiente, Madrid)

Ajuntament de València http://www.valencia. es/ayuntamiento/urbanismo.nsf

http://www.valencia.es/estadistica

Collado V. and Gómez-Pardo. S. (2007) 'Landscape legal framework of the Valencian community". Fifth meeting of the Workshops of the Council of Europe for the implementation of the European Lanscape
Covention. Landscape quality objectives: from theory to practice. (Council of Europe Publishing, Belgium).

Council of Europe. (2000) European Landscape Convention.

Council of Europe. (2013) Glossary of the Council of Europe Information System of the European Landscape Convention.

Esteban i Noguera J. (1981) Elementos de ordenación urbana. (Ed. Gaza Ciència, Barcelona)

Generalitat Valenciana (2016). Plan de Acción Territorial de Ordenación y Dinamización de la Huerta de Valencia. Conselleria de Vivienda, Obras Públicas y Vertebración del Territorio http://www.habitatge.gva.es/web/ planificacion-territorial-e-infraestructuraverde/participacion-publica-pat-huerta

Goldstein, E. B. (2011) Sensación y Percepción. (Ed. Cengage Learning, México).

Hallet, C et al. (1996) 'L'Etat de l'Environnement Wallon'

Lynch, K. (1960): The image of the city. (The MIT Press. Cambridge, Massachusetts). Versión castellana La imagen de la ciudad. (Gustavo Gili, Barcelona)

Mata R. (2003) "Paisajes españoles. Cuestiones sobre su conocimiento. Caracterización e identificación.” En Paisaje y Ordenación del Territorio pp. 33-46 (Junta de Andalucia/ FDS, Sevilla)

Panerai Ph., Castex, J. y Depaule J.C. (1986). Formas Urbanas: de la manzana al bloque (Gustavo Gili, Barcelona)

Pérez Igualada J. (2005) "La Ciudad de la edificación abierta. Valencia, 1946-1988", Tesis Doctoral. Universidad Politécnica Valencia.

Punter, J. V. (1982). 'Landscape aesthetics: A synthesis and critique'. In J. R. Gold \& J. Burgess (Eds.), Valued environments, pp.100-123 (Allen \& Unwin, London)

Rueda, S. (2012). Guía Metodológica para los sistemas de auditoría, certificación o acreditación de la calidad y sostenibilidad en el medio urbano (Ministerio de Fomento/ AEUB, Madrid)

Shafer M. (1977). The Tuning of the World. (Knopf, New York)

Smardon R., Palmer J. and Felleman J. (1986) Foundations for visual project analysis. (John Wiley \& Sons, New York) 
Solà-Morales M. (1997). Las formas de crecimiento urbano (Ediciones UPC, Barcelona)

Swanwick, C. (2002) Landscape Character Assessment: Guidance for England and Scotland. (The Countryside Agency/Scottish Natural Heritage)

Zoido, F. (2010) "Paisaje urbano. Aportaciones para la definición de un marco teórico, conceptual y metodológico". Universidad de Cantabria 